Tohoku J. exp. Med., 1975, 116, 133-139

\title{
Studies on Stereospecific Reduction of Acetoacetyl CoA and Crotonyl CoA in Lactating Rabbit Mammary Glands
}

\author{
Takehiko Takatori* and Yoh ImaI \\ Department of Biochemistry, Hokkaido University School of \\ Medicine, Sapporo
}

\begin{abstract}
Takatori, T. and ImaI, Y. Studies on Stereospecific Reduction of Acetoacetyl CoA and Crotonyl CoA in Lactating Rabbit Mammary Glands. Tohoku J. exp. Med., 1975, 116 (2), 133-139—Stereospecificity as well as the dependency on reduced pyridine nucleotides of the enzymatic reduction of acetoacetyl CoA and crotonyl $\mathrm{CoA}$ in lactating rabbit mammary glands are reported. In the reduction of both acetoacetyl $\mathrm{CoA}$ and crotonyl CoA as substrates the tritium from $\mathrm{NADP}^{3} \mathrm{H}$ was stereospecifically incorporated into the $\beta$-position of $\mathrm{n}$-butyric acid. The reaction of acetoacetyl CoA reduction was much more dependent on NADH while the reduction of crotonyl CoA was rather more dependent on NADPH. There was no difference between the dependencies on NADH and NADPH in the reduction of 2 -hexenyl CoA. —— acetoacetyl CoA; crotonyl CoA; 2hexenyl CoA
\end{abstract}

Fatty acid synthesis in the lactating mammary glands of herbivorous animals appears to differ from that in the other tissues, such as liver or adipose tissue, concerning the formation of short-chain fatty acids. Hele (1958) and Smith and Dils (1966) reported that in the lactating rabbit mammary glands reqirements for reduced pyridine nucleotides in n-butyric acid synthesis were also different from those in long-chain fatty acid synthesis. Although partially purified enzymes from rat-brain tissue catalyzed the stereospecific reduction of crotonyl $\mathrm{CoA}$ to $\mathrm{n}$-butyric acid (Robinson et al. 1962), the reduction mechanism in the formation of n-butyric acid has not been completely clear, because fatty acids synthesized, for example, by rat or pigeon liver, are mostly identified as long-chain fatty acids. We have reported that $\left[1-{ }^{14} \mathrm{C}\right]$ acetate was incorporated into crotonic acid and $\mathrm{n}$-butyric acid as well as middle- and long-chain fatty acids by lactating rabbit mammary glands (Takatori and Imai 1969). Therefore, it is possible to investigate directly whether the reduction of acetoacetyl $\mathrm{CoA}$ to $\beta$-hydroxybutyric acid is stereospecific or not by degradation of $\mathrm{n}$-butyric acid which is produced by hydrogenation of crotonic acid. In this paper we describe the stereospecific reduction of acetoacetyl $\mathrm{CoA}$ and crotonyl $\mathrm{CoA}$ and its dependency on reduced pyridine nucleotides in the reaction with enzyme preparations from the lactating rabbit mammary glands.

Received for publication, March 4, 1975.

* Present Address: Department of Legal Medicine, Hokkaido University School of Medicine. 


\section{Materials and Methods}

Animals. The lactating rabbits which had been suckling for 7 to 21 days post partum were employed in this experiment.

Chemicals. ATP, CoA, NADH, NADPH, NADP+ and D,L- $\beta$-hydroxybutyric acid were obtained from Sigma Chemical Co.; $\left[1-{ }^{3} \mathrm{H}\right]$ glucose, from New England Nuclear Corp.; glucose-6-phosphate dehydrogenase and hexokinase, from Boehringer and Mannheim; Dowex $1 \times 4 \mathrm{Cl}$ type (200-400 mesh), from Dow Chemical Co.; and all other reagents were from Wako Pure Chemical Ind., Japan. Acetoacetyl CoA was prepared according to either Robinson et al. (1963) or Lynen and Wieland (1955). A better recovery of acetoacetyl CoA was obtained by the latter method which employed diketene. The purity of the chemically synthesized acetoacetyl CoA was determined by the method of Seubert et al. (1968) assuming that the molar extinction coefficient of acetoacetyl CoA at $313 \mathrm{~nm}$ is $8.85 \times 10^{6}$ in $0.1 \mathrm{M}$ tris-HCl buffer ( $\mathrm{pH} \mathrm{8.9}$ ) containing $5 \mathrm{mM} \mathrm{MgCl}_{2}$. Crotonyl CoA and 2-hexenyl CoA were prepared according to the method of Stadtman (1957). All CoA derivatives were purified by paper chromatography.

Preparation of crude enzyme sourse. Preformed milk was removed manually as much as possible before the rabbit was killed. The inguinal and abdominal mammary glands were taken under light ether anesthesia, chilled in cracked ice, and then the fibrous tissues were removed. These mammary glands were excised, washed several times with 0.3 M sucrose to further remove the performed milk, and homogenized with 3 volumes of 0.3 $M$ sucrose in a Potter-Elvehjem homogenizer. The crude homogenate was centrifuged at $12,000 \times \mathrm{g}$ to yield a supernatant fraction without cell debris. The mitochondria were removed from this fraction by centrifugation at $50,000 \times \mathrm{g}$. The supernatant fraction obtained after sedimenting the mitochondria was designated as fraction $(M+S)$, containing the microsomal and particle-free supernatant fractions (Smith and Dils 1966). The fraction $(M+S)$ was recentrifuged at $50,000 \times \mathrm{g}$ and the supernatant obtained was dialyzed for $12 \mathrm{hr}$ with $50 \mathrm{mM}$ potassium phosphate buffer ( $\mathrm{pH} 7.0$ ) containing $10 \mathrm{mM}$ 2-mercaptoethanol, and this was designated as $(M+S)_{D}$. All the above procedures were carried out at $4^{\circ} \mathrm{C}$. Protein content was determined by the method of Lowry et al. (1951), using bovine serum albumin as a standard.

Incubation system for synthesis of crotonic acid and $n$-butyric acid. The reaction was carried out in a test tube which contained, in a final volume of $1 \mathrm{ml}, 50 \mu$ moles of potassium phosphate buffer ( $\mathrm{pH} \quad 7.0$ ), $10 \mu$ moles of 2-mercaptoethanol, [1-3 $\mathrm{H}]$ glucose (approximately $30 \mu \mathrm{Ci}), 3.3 \mu$ moles of $\mathrm{MnCl}_{2}$, $15 \mu$ moles of ATP, $2 \mu$ moles of NADP+, glucose-6phosphate dehydrogenase $(0.3$ unit), hexokinase $(12.8$ units), either 500 nmoles of acetoacetyl CoA or 470 nmoles of crotonyl CoA, and enzyme protein $\left((M+S)_{D},(5.3 \mathrm{mg})\right.$, for $\mathrm{l} \mathrm{hr}$ at $37^{\circ} \mathrm{C}$ under nitrogen.

Extraction of fatty acids. After the incubation, the reaction was stopped by the addition of $1 \mathrm{ml}$ of a mixture of $40 \% \mathrm{KOH}$ and ethanol $(7: 3, \mathrm{v} / \mathrm{v})$, saponified for $1 \mathrm{hr}$ at $80^{\circ} \mathrm{C}$, and then acidified with $1 \mathrm{ml}$ of conc. $\mathrm{HCl}$. Total fatty acids were extracted 4 times with 4 volumes of diethylether. To the combined extracts was added anhydrous sodium sulfate, and finally ether was evaporated gently in a chilled water bath under a stream of nitrogen. Under this evaporation condition, loss of short-chain fatty acids was negligible.

Analysis of short-chain fatty acids. Short-chain fatty acids were separated by a thermodetective liquid chromatograph (JLC-2A type, Nihon Denshi, Japan) with ion exchange resin as described previously (Takatori and Imai 1969), The thermogram of acetic to $n$-valeric acids was shown in Fig. 1 . The residue of fatty acids extracted was dissolved first in $0.3 \mathrm{ml}$ of methanol and then an equal volume of distilled water was added to it. 0.3 to $0.5 \mathrm{ml}$ of the solution was injected with a syringe into a sample inlet at a top of a separation column. Both crotonic acid and n-butyric acid fractions were collected and 
made alkaline with $\mathrm{NaOH}$. Total radioactivities of respective fatty acid fractions were measured with Bray's solution (1960) in a liquid scintillation spectrometer (Aloka, Japan).

Microdegradation procedure. The tritiated n-butyric acid, which was synthesized from crotonyl CoA in the presence of $\mathrm{NADP}^{3} \mathrm{H}$, was separated by the liquid chromatography and subjected to stepwise degradation exactly following the methods of Phares (1951) and Robinson et al. (1962). Propylamine formed, after decarboxylation of n-butyric acid in the first step of degradation, was oxidized to propionic acid and water with $10 \% \mathrm{KMnO}_{4}$. The resulting mixture was made strongly alkline with $\mathrm{KOH}$, and the water was recovered by distillation and examined for radioactivity. The resulting salts were then converted to acids, and propionic acid and slightly formed acetic acid were again separated by the liquid chromatography. Propionic acid recovered was further degraded in the same manner, and water formed was counted. On the other hand, the tritiated crotonic acid, which was produced from acetoacetyl $\mathrm{CoA}$ as substrate, was converted to n-butyric acid by hydrogenation with palladium oxide. The n-butyric acid was then degraded in the same manner as above.

Reduction rate of acetoacetyl CoA, crotonyl CoA and 2-hexenyl CoA. Either 507 nmoles of acetoacetyl CoA, 282 nmoles of crotonyl CoA or 500 nmoles of 2-hexenyl CoA were added to $3 \mathrm{ml}$ of $50 \mathrm{mM}$ potassium phosphate buffer $(\mathrm{pH} 7.0)$ containing $50 \mathrm{mM}$ 2-mercaptoethanol, $0.3 \mu$ moles of either NADH or NADPH, and enzyme protein $\left((M+S)_{D}, 2.4 \mathrm{mg}\right)$. The decrease in absorbance of each cuvette after addition of substrate was read at $340 \mathrm{~nm}$ in $1 \mathrm{~cm}$ quartz cell at room temperature.

\section{Results}

Short-chain fatty acids of acetic to $n$-valeric acids were completely separated by the thermodetective liquid chromatography (Fig. 1).

The reduction product of acetoacetyl CoA in the presence of $\mathrm{NADP}^{3} \mathrm{H}$ with the crude enzyme preparation was fractionated as ${ }^{3} \mathrm{H}$-crotonic acid and ${ }^{3} \mathrm{H}-\mathrm{n}-$ butyric acid by the liquid chromatography, and that of crotonyl-CoA as ${ }^{3} \mathrm{H}-\mathrm{n}-$ butyric acid. The radioactivities recovered in crotonic acid and $n$-butyric acid

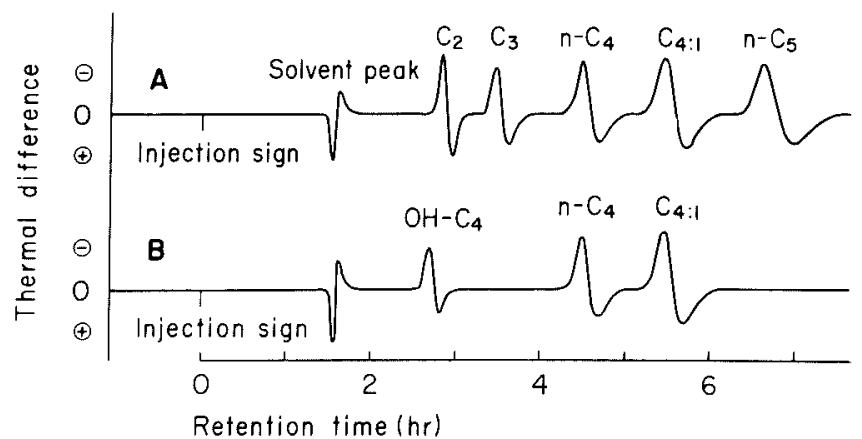

Fig. 1. A: The thermogram of acetic to n-valeric acids. The temperature of the detection and separation column was set at 30 and $50^{\circ} \mathrm{C}$, and the flow rate and sensitivity were adjusted to $0.38 \mathrm{ml} / \mathrm{min}$ and $\pm 3 / 1000^{\circ} \mathrm{C}$ full scale, respectively. Each 5 and $2.5 \mathrm{mg}$ of $\mathrm{C}_{2}, \mathrm{C}_{3}, \mathrm{n}-\mathrm{C}_{4}$ and $\mathrm{n}-\mathrm{C}_{5}$, and $\mathrm{C}_{4: 1}$ were injected, respectively. $\mathrm{B}$ : The thermogram of $\mathrm{D}, \mathrm{L}-\beta$-hydroxybutyric, $\mathbf{n}$-butyric and crotonic acids. All developing conditions were the same as for Fig. 1-A except that $5 \mathrm{mg}$ of $\mathrm{D}, \mathrm{L}-\beta$-hydroxybutyric acid were injected. 
TABLE 1. Distribution of tritium in ${ }^{3} H$-crotonic acid synthesized from acetoacetyl CoA in the presence of $N A D P^{3} \mathrm{H}$

\begin{tabular}{cccc} 
& \multicolumn{3}{c}{ Distribution of ${ }^{3} \mathrm{H}(\%)$} \\
\cline { 2 - 4 } Exp. No. & \multicolumn{3}{c}{ Position of carbon } \\
\hline 1 & $\alpha$ & $\beta$ & $\gamma$ \\
\hline 2 & 7 & 93 & 0 \\
\hline
\end{tabular}

TARLE 2. Distribution of tritium in ${ }^{3} H-n$-butyric acid synthesized from cratonyl $\mathrm{CoA}$ in the presence of $\mathrm{NADP} P^{3} \mathrm{H}$

\begin{tabular}{cccc} 
& \multicolumn{3}{c}{ Distribution of ${ }^{3} \mathrm{H}(\%)$} \\
\cline { 2 - 4 } Exp. No. & \multicolumn{3}{c}{ Position of carbon } \\
\hline 1 & $\alpha$ & $\beta$ & $\gamma$ \\
\hline 2 & 8 & 92 & 0 \\
& 4 & 96 & 0 \\
\hline
\end{tabular}

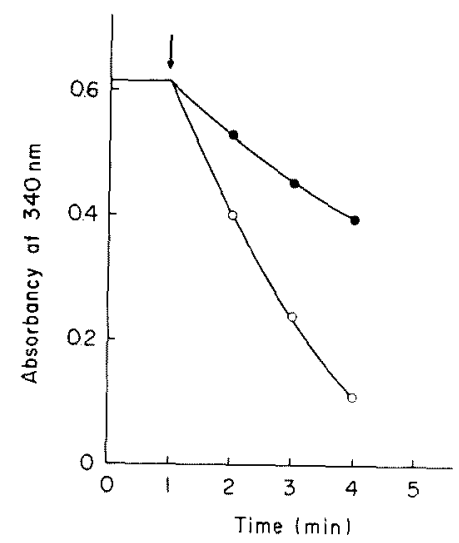

Fig. 2. Spectrophotometric demonstration of the reduction of acetoacetyl CoA. The substrate was added at the arrow. For details see text. 0 , NADH; $\bullet$ NADPH.

from acetoacetyl CoA were 21,000 and $86,400 \mathrm{cpm}$ on the average of two experiments, respectively, and those in n-butyric acid from crotonyl CoA were $37,000 \mathrm{cpm}$ on the average of two experiments. As shown in Table 1, approximately $93 \%$ of the total tritiated water, which was formed by degradation, was found to be localized at the $\beta$-position of the $\mathbf{n}$-butyric acid which was obtained by hydrogenation of ${ }^{3} \mathrm{H}$-crotonic acid formed from acetoacetyl CoA. Likewise, when ${ }^{3} \mathrm{H}-\mathbf{n}$ butyric acid formed from crotonyl CoA was degraded, approximately $94 \%$ of the total tritium was localized at the $\beta$-position of the $n$-butyric acid (Table 2).

Smith and Dils (1966) have reported that $n$-butyric acid synthesis was more dependent on $\mathrm{NADH}$ in the lactating rabbit mammary glands. Thus, the 


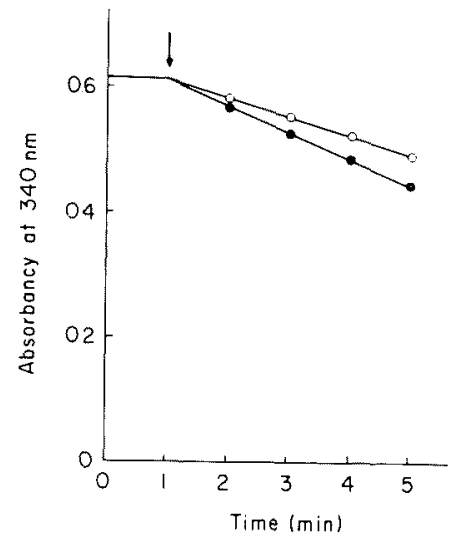

Fig. 3. Spectrophotometric demonstration of the reduction of crotonyl CoA. The substrate was added at the arrow. For details see text. o, NADH; •, NADPH.

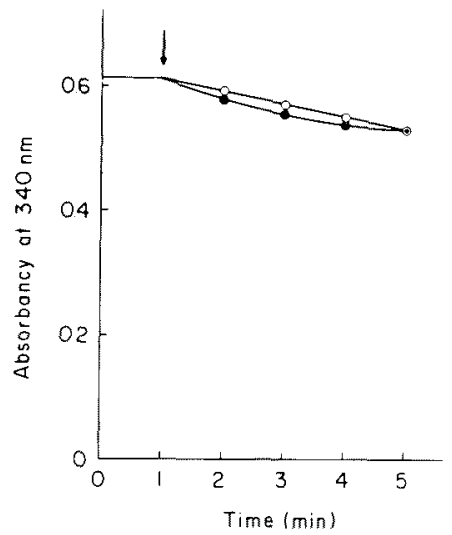

Fig. 4. Spectrophotometric demonstration of the reduction of 2 -hexenyl CoA. The substrate was added at the arrow. For details see text. $\quad$, NADH; •, NADPH.

dependencies on NADH and NADPH in the course of reduction of n-butyric acid synthesis were also compared. When acetoacetyl CoA was used as substrate, both $\mathrm{NADH}$ and NADPH were effective and the overall reduction was much more dependent on NADH (Fig. 2). In the reduction of crotonyl CoA to n-butyric acid, likewise, both $\mathrm{NADH}$ and NADPH were effective and NADPH was rather more effective than $\mathrm{NADH}$ (Fig. 3). When 2-hexenyl CoA was used as substrate, there was little difference in dependency on $\mathrm{NADH}$ and NADPH as seen in Fig. 4, and the reaction rate was lower as compared with other substrates.

\section{Discussion}

In the present paper we demonstrated the stereospecific reduction of acetoacetyl $\mathrm{CoA}$ to $\beta$-hydroxybutyric acid and of crotonyl $\mathrm{CoA}$ to $\mathrm{n}$-butyric acid 
by the crude enzyme preparations from the lactating rabbit mammary glands. Tritiated NADPH was used in this study mainly because it was easier to enzymatically synthesize $\mathrm{NADP}{ }^{3} \mathrm{H}$ than $\mathrm{NAD}^{3} \mathrm{H}$, although the reduction of acetoacetyl $\mathrm{CoA}$ was more dependent on NADH (Fig. 2). As shown in Table 1, the tritium from $\mathrm{NADP}^{3} \mathrm{H}$ was incorporated markedly at the $\beta$-position of crotonic acid formed enzymatically from acetoacetyl CoA via $\beta$-hydroxybutyric acid. Moreover, in the course of the reduction of crotonyl $\mathrm{CoA}$, the tritium from $\mathrm{NADP}^{3} \mathrm{H}$ was also localized at the $\beta$-position of $n$-butyric acid (Table 2). These results suggest that the hydrogen transfer can occur at both steps in the reduction of $\beta$-keto derivative to the saturated compound. They also indicate that the hydrogen atom which was incorporated into $\mathrm{n}$-butyric acid from reduced pyridine nucleotides may well remain in the molecule. Marcus et al. (1958) reported that $\beta$-hydroxybutyryl dehydrogenase from pig liver had $\beta$-stereospecificity for NADH, and Robinson et al. (1962) demonstrated that tritium from $\mathrm{NADP}^{3} \mathrm{H}$ was incorporated into the $\beta$ position of $n$-butyric acid in the reduction of crotonyl CoA by rat-brain tissue. These findings are consistent with the present enzymatic studies. In the course of middle- and long-chain fatty acid synthesis by lactating rabbit mammary glands, the hydrogen transfer from NADPH or NADH would probably occur also successively on alternate carbon atoms beginning with the $\beta$-carbon of middle- and long-chain fatty acids (Brady et al. 1960).

The spectrophotometric data indicated that the overall formation of $n$-butyric acid was more dependent on NADH, and both NADH and NADPH appeared to be effective in the synthesis of middle- and long-chain fatty acids (Figs, 2, 3 and 4). Previously we reported that when $\left[1-{ }^{14} \mathrm{C}\right]$ acetate was incubated with crude enzyme preparations from lactating rabbit mammary glands, practically no $\beta$-hydroxybutyric acid was formed as judged by both radio-gas chromatography and liquid chromatography (Takatori and Imai 1969). This may be due to that the reaction rate of conversion of $\beta$-keto to $\alpha, \beta$-unsaturated compound is much faster. Brady et al. (1960) and Lynen (1961) showed that enzyme preparations from pigeon liver and yeast did not incorporate $\beta$-keto, $\beta$-hydroxy and $\alpha, \beta$-unsaturated CoA derivatives into long-chain fatty acids. However, the lactating rabbit mammary glands were capable of utilizing all three $\mathrm{CoA}$ derivatives.

Some other radioactive substances (not shown here) as well as ${ }^{3} \mathrm{H}$-crotonic acid and ${ }^{3} \mathrm{H}-\mathrm{n}$-butyric acid were recovered from the reaction mixtures containing acetoacetyl $\mathrm{CoA}$ and/or crotonyl $\mathrm{CoA}$ and $\mathrm{NADP}^{3} \mathrm{H}$. These may be due to concomitant synthesis of middle- and long-chain fatty acids resulted by successive condensations with malonyl CoA remaining in the crude enzyme preparations.

\section{References}

1) Brady, R.O., Bradley, R.M. \& Trams, E.G. (1960) Biosynthesis of fatty acids. 1. Studies with enzymes obtained from liver. J. biol. Chem., 235, 3093-3098.

2) Bray, G.A. (1960) A simple efficient liquid scintillator for counting aqueous solutions in a liquid scintillation counter. Anal. Biochem., 1, 279-285.

3) Hele, P. (1958) Biosynthesis of fatty acids. Brit. med. Bull., 14, 201-206. 
4) Lowry, O.H., Rosebrough, N.J., Farr, A.L. \& Randall, R.J. (1951) Protein measurement with the folin phenol reagent. J. biol. Chem., 193, 265-275.

5) Lynen, F. (1961) Biosynthesis of saturated fatty acids. Fed. Proc., 20, 941-951.

6) Lynen, F. \& Wieland, O. (1955) $\beta$-Ketoreductase. In: Methods in Enzymology, edited by S.P. Colowick \& N.O. Kaplan, Academic Press, New York, Vol. 1, pp. 566-573.

7) Marcus, A., Vennesland, B. \& Stern, J.R. (1958) The enzymatic transfer of hydrogen. VII. The reaction catalyzed by $\beta$-hydroxybutyryl dehydrogenase. $J$. biol. Chem., 233, 722-726.

8) Phares, E.F. (1951) Degradation of labeled propionic and acetic acids. Arch. Biochem. Biophys., 33, 173-178.

9) Robinson, J.D., Bradley, R.M. \& Brady, R.O. (1963) Biosynthesis of fatty acids. III. Utilization of substituted acyl Coenzyme A derivatives as intermediates. $J$. biol. Chem., 238, 528-532.

10) Robinson, J.D., Brady, R.O. \& Maxwell, C.R. (1962) Stereospecific reduction of crotonyl Coenzyme A. J. Lipid Res., 3, 243-245.

11) Seubert, W., Lamberts, I., Kramer, R. \& Ohly, B. (1968) On the mechanism of malonyl-CoA-independent fatty acid synthesis. 1. The mechanism of elongation of longchain fatty acids by acetyl-CoA. Biochim. biophys. Acta (Amst.), 164, 498-517.

12) Smith, S. \& Dils, R. (1966) Factors affecting the chain length of fatty acids synthesised by lactating-rabbit mammary glands. Biochim. biophys. Acta (Amst.), 116, 23-40.

13) Stadtman, E.R. (1957) Preparation and assay of acyl Coenzyme A and other thiol esters; Use of hydroxylamine. In: Methods in Enzymology, edited by S.P. Colowick \& N.O. Kaplan, Academic Press, New York, Vol. 3, pp. 931-941.

14) Takatori, T. \& Imai, Y. (1969) Biosynthesis of fatty acids in lactating rabbit mammary glands. Proc. Jap. Conf. Biochem. Lipids (Jap.), 11, 241-243. 